Keywords: Complex posttraumatic stress disorder; Asylum seekers; Interpersonal trauma; Human trafficking; Domestic violence; Torture.

\title{
Complex posttraumatic stress disorder in traumatised asylum seekers: A pilot study
}

\section{Madeleine Kissane* Lawrence Szymanski* Rachel Upthegrove* Cornelius Katona**}

* College of Medical and Dental Sciences, University of Birmingham

** Medical Director, Helen Bamber Foundation

ENGLAND

\begin{abstract}
Background and Objectives: Complex posttraumatic stress disorder (cPTSD), a construct associated with early onset and repeated interpersonal trauma, has not previously been assessed in asylum seekers who have experienced major human rights violations. The aim of this pilot study was to describe the cPTSD symptom profile in asylum seekers, and to compare this profile between three groups of people who have experienced: human trafficking, domestic violence and/or torture.

Methods: Over a period of eight weeks, clinicians working at the Helen Bamber Foundation charity invited 48 patients currently receiving psychotherapy to take part in the study, of whom 30 (62.5\%) agreed. The structured interview for disorders of extreme stress (SIDES) was used to assess cPTSD in 29 asylum seekers, as one patient withdrew during the interview.

Results: Participants originated from 18 countries, $72.4 \%$ were female, the median age at trauma onset was 17 years and the duration of trauma was ten years. Eight (27.6\%) participants were found to have cPTSD, defined as having all six symptom clusters, and 15 $(51.7 \%)$ had five or more cPTSD symptom clusters. Age at trauma onset, duration of trauma, last trauma experience, gender and trauma type were not found to be associated with cPTSD presence.

Conclusions: Extensive cPTSD symptoms were common in all participants, regardless of the nature of the trauma experienced. Future research is needed to enable generalisability of cPTSD symptom profile in asylum seekers.
\end{abstract}




\section{Introduction}

The psychological consequences of exposure to trauma were extensively researched in Vietnam War veterans, which led to the development of diagnostic criteria for posttraumatic stress disorder (PTSD) ${ }^{1}$. Additional symptoms were subsequently identified in individuals with PTSD who had suffered from childhood abuse, suggesting that the previously existing PTSD criteria did not capture all aspects of traumatic symptomatology ${ }^{2}$. The diagnostic category of complex PTSD (cPTSD) has been proposed as a form of PTSD, linked with early onset and prolonged interpersonal trauma ${ }^{3}$. cPTSD encompasses components of other psychiatric conditions such as mood and dissociative disorders. It is therefore a complicated condition with a poor prognosis and treatment efficacy ${ }^{3-6}$.

There is incomplete agreement regarding cPTSD, a term used synonymously with Disorders of Extreme Stress Not Otherwise Specified (DESNOS), in classification manuals. Within the $4^{\text {th }}$ edition of the Diagnostic and Statistical Manual for Mental Disorders (DSM-IV), it was not recognised as a diagnostic category though its symptoms were categorised under 'associated features of PTSD' 7 . Recent changes in the DSM-5 have expanded the PTSD criteria and have included a 'dissociative' subtype ${ }^{8}$. In contrast, the forthcoming $11^{\text {th }}$ edition of the International Classification of Diseases proposed a separate diagnosis of cPTSD which does not include dissociative features 9 . The Structured Interview for Disorders of Extreme Stress (SIDES) was developed to identify the presence of DESNOS, and at the time of research was its only validated measure in use $\mathrm{e}^{10,11}$.

Few studies on cPTSD have been in nonWestern populations and there is a dearth of research in refugee groups. The manifestation of
cPTSD in these more varied populations requires further description and exploration ${ }^{10}$. Two studies focused on conflict zone inhabitants in Kosova, Ethiopia, Gaza and Algeria $^{12,13}$, one investigated Bosnian refugees ${ }^{14}$ and, most recently, one investigated refugees living in Norway ${ }^{15}$. All these studies found much lower prevalences of cPTSD and its key symptoms compared to Western populations, thereby raising concerns as to the cross-cultural validity of the construct ${ }^{12}$. In refugee samples, PTSD has been shown to be common amongst victims of human trafficking, domestic violence and torture, though cPTSD has received little attention in this area ${ }^{16-18}$. Two small studies in non-refugee samples investigated German victims of torture and domestic violence and found high cPTSD prevalence, whilst none have investigated human trafficking ${ }^{19,20}$. The effect of major human rights violations on the presence of cPTSD in asylum-seeking populations has never been researched. This pilot study thus aims to assess the prevalence and clinical features of cPTSD in asylum-seeking survivors of torture, domestic violence and human trafficking.

\section{Methods}

\section{Sample}

A convenience sampling method was used to recruit patients from the Helen Bamber Foundation (HBF), a London-based charity supporting asylum-seeking survivors of human rights violations. An asylum seeker was defined as someone who has applied for protection as a refugee and is awaiting the determination of his or her status ${ }^{21}$. Patients had been referred to the HBF for trauma-focused psychotherapy by their legal representatives or health care professionals. Over a period of 8 weeks, HBF clinicians invited 
48 patients currently receiving psychotherapy to take part in the study, of whom $30(62.5 \%)$ agreed to participate. Twenty nine $(60 \%)$ completed the study; one participant withdrawing from the interview after consent.

\section{Procedure}

HBF patients were recruited if they were aged over 18 , their therapists considered that their participation would not interfere with therapy, and were able to give informed consent. Data were collected by MK or LS using the SIDES, with the assistance of HBF interpreters in seven interviews (24\%). MK and LS received ongoing supervision from $\mathrm{CK}$, an academic psychiatrist with extensive knowledge and experience working with this clinical group, regarding the interview process.

Demographic variables (gender, age, nationality) and trauma characteristics (trauma type, age at onset of trauma, duration of trauma and time since last episode of trauma) were collected once the interview had taken place. Participants were categorised into one or more of human trafficking, torture and domestic violence groups by HBF clinicians using United Nations and Home Office definitions) $)^{22-24}$.

\section{Measures}

cPTSD symptoms were assessed using the SIDES, a 45 item structured interview which measures the 24 symptoms of cPTSD. These symptoms are then grouped, generating six symptom clusters: I - alterations in affect regulation, II - alterations in consciousness, III - alterations in self-perception, IV - alterations in relations, $\mathrm{V}$ - somatisation, and $\mathrm{VI}$ - alterations in meaning. Each item assesses lifetime presence, and is then graded from 0 to 3 for current severity, over 2 signi- fying current presence. cPTSD requires all six symptom clusters to be present ${ }^{15}$. These calculations were carried out according to the SIDES authors' "Trauma Assessment Packet \& Software" (van der Kolk \& Smyth, 2003). The SIDES has high internal consistency (Cronbach's $\alpha=0.96$ ) and excellent inter-rater reliability (kappa 0.88-1.00) ${ }^{10}$. The internal consistency in the present study was $\alpha=0.80$.

\section{Analyses}

The data were not normally distributed, therefore non-parametric tests were used. Demographic variables, trauma characteristics and CPTSD profile were analysed using proportions and medians with interquartile ranges where appropriate. Correlations were assessed using Spearman's rank tests. Mann-Whitney U, Chi-Square and Fisher's exact tests were used for comparisons between groups.

To analyse trauma groups, all those who had experienced human trafficking were compared to those who had not. The same comparison was repeated for domestic violence and torture groups. This approach was used because analysing pure trauma groups would have excluded individuals with multiple trauma types, resulting in very small comparison groups.

\section{Results}

Of the 29 participants, $20(72.4 \%)$ were female and the median age was 32 years (interquartile range (IQR): 27.5 - 37). The participants originated from 18 countries, $20(69 \%)$ came from Africa, seven (24.2\%) from Asia, one $(3.4 \%)$ from Albania and one from Trinidad and Tobago. The most prevalent na- 
tionalities were Nigerian ( $n=4,13.8 \%)$, Ugandan $(n=4,13.8 \%)$ and Turkish $(n=3$, $10.3 \%$ ). The median age at onset of trauma was 17 years (IQR 9-22.5), duration of trauma was ten years (IQR 5-16) and time since last trauma experience was five years (IQR 3-8.5).

The most common type of trauma was torture, with nine participants $(31 \%)$ having experienced it. Eight participants $(27.6 \%)$ had experienced human trafficking and four $(13.8 \%)$ were survivors of domestic violence. Eight participants $(27.6 \%)$ had experienced multiple types of trauma, of which five (17.3\%) experienced domestic violence and human trafficking, two $(6.9 \%)$ human trafficking and torture and one (3.4\%) domestic violence and torture.

Eight participants (27.6\%) had current presence of cPTSD, as defined by the manifestation of all six symptom clusters. Seven (24\%) had five clusters present; cluster VI (alterations in meaning) was absent in five out of these seven. All had the current presence of one or more clusters and only one participant had a single cluster. Clusters II (alterations in consciousness) and IV (alterations in relations) were both present in 28 out of 29 participants, whereas clusters V (somatisation) and VI were the least frequent but still occurred in $51.7 \%$ and $44.8 \%$ of participants respectively. Lifetime presence for all symptoms was higher than current presence. All clusters had been experienced by $86 \%$ and only three individual symptoms (excessive risk taking, victimising others, sexual and cardiopulmonary somatisation) had been experienced by less than $50 \%$ of participants in their lifetime (See Table 1).

Age at onset of trauma $(r=0.094, p=0.63)$, duration of trauma $(r=0.064, p=0.74)$ and time since last trauma experience $(r=0.07$, $p=0.719)$ were not significantly correlated with the number of cPTSD clusters present or any individual cluster's presence. Gender was not significantly associated with the number of cPTSD clusters present, but cluster III (alterations in self-perception) was over twice as common in females $(81 \%$ v. $37.5 \%, z=-2.221$, $p=0.026$ ), whilst cluster VI (alterations in meaning) was twice as common in males (75\%. v. 33.5\%, $z=-1.981, p=0.048)$.

\section{Comparisons between trauma groups}

The torture group had significantly fewer females than the non-torture group (females: $50 \%$ v. $88.2 \%, p=0.038$ ). Torture victims also had a later onset of trauma ( $M d n 15 \mathrm{v} .9$ years, $z=-2.841, p=0.004)$ and a shorter trauma duration $(M d n 10$ v. 16 years, $z=-2.774$, $p=0.006)$. The human trafficking group had a greater proportion of females compared to the non-human trafficking group, but this was not significant (females $86.7 \%$ v. $42.9 \%$, $p=0.109)$. They also had an earlier onset of trauma ( $M d n 12$ v. 19 years, $z=-1.991$, $p=0.046)$ and a longer trauma duration $(M d n$ 12 v. 5 years, $z=-2.1, p=0.036$ ). Participants who had experienced domestic violence had an earlier onset of trauma $(M d n 10 \mathrm{v} .19$ years, $z=-2.438, p=0.015)$.

Only one of the 6 symptom clusters (cluster VI - alterations in meaning) differed significantly in lifetime prevalence between trauma groups: it was experienced 2.5 times more often in the non-human trafficking group compared to the human trafficking group $\left(24.6 \%\right.$ v. $\left.64.3 \%, \chi^{2}-4.114, p=0.042\right)$. The only significant difference in current presence of cPTSD between torture victims and non-torture victims, was that torture victims exhibited the current presence of cluster VI three times more often than non-torture victims $\left(75 \%\right.$ v. $\left.23.5 \%, \chi^{2}=7.535, p=0.006\right)$. No aspects of cPTSD significantly differed between domestic violence and non-domestic violence victims. 
Table 1

Complex posttraumatic stress disorder cluster and symptom frequencies and severity scores in traumatised asylum seekers as measured by the Structured Interview for Disorders of Extreme Stress (SIDES) ( $=29$ ).

\begin{tabular}{|c|c|c|c|}
\hline Symptom clusters & $\begin{array}{l}\text { Lifetime } \\
\text { Presence } n(\%)\end{array}$ & $\begin{array}{l}\text { Current Presence } \\
n(\%)\end{array}$ & $\begin{array}{l}\text { Severity/3 } \\
\text { Median (IQR) }\end{array}$ \\
\hline I - Alteration in affect regulation & $26(89.6)$ & $22(75.9)$ & $1.1(0.8-1.3)$ \\
\hline a. Affect & $26(89.6)$ & $22(75.9)$ & $2(1-2.5)$ \\
\hline b. Anger & $22(75.9)$ & $21(72.4)$ & $2(0-2.5)$ \\
\hline c. Self-destructive & $22(75.9)$ & $3(10.4)$ & $0(0)$ \\
\hline d. Suicidal & $22(75.9)$ & $1(3.4)$ & $0(0)$ \\
\hline e. Sexual involvement & $28(96.6)$ & $22(75.9)$ & $2.5(1-3)$ \\
\hline f. Risk taking & $11(37.9)$ & $3(10.4)$ & $0(0)$ \\
\hline II - Alterations in consciousness & $29(100)$ & $28(96.6)$ & $1.5(1-2.5)$ \\
\hline a. Amnesia & $20(69)$ & $14(44.8)$ & $0(0-3)$ \\
\hline b. Dissociation & $28(96.6)$ & $26(89.6)$ & $2(2-2.67)$ \\
\hline III - Alterations in self-perception & $28(96.6)$ & $20(69)$ & $0.8(0.5-1.3)$ \\
\hline a. Ineffectiveness & $22(75.9)$ & $5(17.2)$ & $0(0)$ \\
\hline b. Damage & $24(82.8)$ & $19(65.5)$ & $2(0-3)$ \\
\hline c. Guilt & $22(75.9)$ & $11(37.9)$ & $0(0-3)$ \\
\hline d. Shame & $24(82.8)$ & $20(69)$ & $3(0-3)$ \\
\hline e. Nobody can understand & $23(79.3)$ & $11(37.9)$ & $0(0-2)$ \\
\hline f. Minimising & $15(51.7)$ & $4(13.8)$ & $0(0)$ \\
\hline IV - Alterations in relations & $28(96.6)$ & $28(96.6)$ & $0.8(0.7-1)$ \\
\hline a. Trust & $29(100)$ & $27(93.1)$ & $2(2-2.5)$ \\
\hline b. Revictimisation & $20(69)$ & $7(24.1)$ & $0(0-1)$ \\
\hline c. Victimising others & $3(10.4)$ & $1(3.4)$ & $0(0)$ \\
\hline V-Somatisation & $25(86.2)$ & $15(51.7)$ & $0.8(0.4-1.3)$ \\
\hline a. Digestive & $18(62.1)$ & $9(31)$ & $0(0-2)$ \\
\hline b. Chronic pain & $22(75.9)$ & $14(48.3)$ & $0(0-2)$ \\
\hline c. Cardiopulmonary & $11(37.9)$ & $8(27.6)$ & $0(0-2)$ \\
\hline d. Conversion & $22(75.9)$ & $14(48.3)$ & $0(0-2)$ \\
\hline e. Sexual & $14(48.3)$ & $11(37.9)$ & $0(0-2)$ \\
\hline VI - Alterations in meaning & $28(96.6)$ & $13(44.8)$ & $0(0-1.9)$ \\
\hline a. Foreshortened future & $26(89.6)$ & $11(37.9)$ & $0(0-2.17)$ \\
\hline b. Loss of beliefs & $28(96.6)$ & $9(31)$ & $0(0-2)$ \\
\hline
\end{tabular}

Note: $\mathrm{n}=$ Number of participants, IQR = Interquartile range. 


\section{Discussion}

This study demonstrated the extensive presence of cPTSD symptomatology in victims of human trafficking, torture and domestic violence. The rigorous criteria used to diagnose cPTSD resulted in a quarter of participants experiencing the disorder. An additional quarter suffered from extensive cPTSD symptoms, indicated by experiencing 5 out of the 6 symptom clusters. All the symptom clusters were frequently reported at clinically significant levels, with 'alterations in consciousness' and 'alterations in relations' present in all except one of the participants. 'Dissociation' and 'lack of trust' were the most frequently experienced symptoms and were responsible for the presence of these two most common clusters. The majority of participants suffered from almost all symptoms at some point in their life, as found in other studies ${ }^{15,25}$.

The prevalence cPTSD in our cohort is in keeping with two German studies which found cPTSD in $27 \%$ of domestic violence victims and $70 \%$ of torture victims ${ }^{19,20}$. However, the cPTSD symptom profile in this group is distinct from previously studied nonWestern populations, as the least frequent clusters were 'alterations in meaning' and 'somatisation', in contrast to previous studies which found them to be the most frequent ${ }^{14,15}$.

In prior research, cPTSD has been found to afflict those who have experienced early onset and prolonged interpersonal trauma ${ }^{3,26}$. This study does not support this, since neither trauma duration nor age at onset of trauma correlated with cPTSD presence. Despite this, earlier trauma was strongly associated with longer trauma duration. Time since last trauma experience was also not significant in affecting symptoms, suggesting the chronic nature of cPTSD psychopathology in this population.
The overall prevalence of cPTSD did not differ between human trafficking, torture and domestic violence victims, despite cluster presence differing significantly. However, the difference in cluster prevalence may be due to the gender proportions of trauma groups: males were three times more likely to experience 'alterations in meaning', and there was a larger proportion of males in the torture group and a smaller proportion in the human trafficking group. Females were also over twice as likely to experience 'alterations in self-perception' than males. Despite this, gender was not found to affect the overall presence of cPTSD. Further research in larger cohorts is needed to clarify and expand on these findings.

This study has several limitations. As this is a pilot study, the small sample size increases the likelihood of false negative findings. The number of comparisons that have been carried out limits the power of significant findings due to the likelihood of type 1 errors. Convenience sampling was used and recruitment was left to the clinicians' discretion, who may have been protective of their most vulnerable patients. The questionable cross-cultural validity of the SIDES may be a limitation in this study as suggested by de Jong et al. ${ }^{12}$. Additionally, it is not known if the $40 \%$ who declined to participate differed from the study sample. Trauma type comparisons should be treated cautiously due to the lack of detail depth regarding traumatic experiences, including childhood trauma. The lack of correlation between age of trauma onset and cPTSD may be due to the lack of knowledge about participants' childhood experiences. It would be beneficial to acquire information about the intensity and character of traumatic experiences, thereby allowing for more valid comparisons.

The SIDES questionnaire was developed in relation to a diagnostic system that has now been superseded. An equivalent diag- 
nostic interview linked to the ICD-11 model of cPTSD is in development. It would be highly desirable to replicate this study in a larger cohort using the new tool. Furthermore, the benefit of diagnosing cPTSD in this population and the effect that symptom presence has on treatment outcome needs to be documented.

This pilot study has displayed that cPTSD may be present in a large proportion of asylum-seeking victims of human trafficking, torture and domestic violence. A greater awareness of cPTSD prevalence in this population is needed to aid therapeutic decisions and resource allocation. The recommended therapy for cPTSD, including phase-based or sequenced therapy with interventions tailored to specific symptom sets, by the International Society for Trauma Stress Studies expert consensus, also needs to be trialled in asylum seekers with cPTSD to assess efficacy ${ }^{27}$.

In conclusion, the fact that over half of participants experienced extensive cPTSD symptomatology and thus, may undergo more severe depressive and anxiety symptoms is clinically important. Undiagnosed cPTSD in this population may be currently hindering treatment efficacy and the adaption of trauma-focused psychotherapy to fit the symptoms experienced by traumatised asylum seekers is necessary.

\section{Acknowledgments}

This research was supported and funded by the Helen Bamber Foundation and the University of Birmingham. Madeleine Kissane and Lawrence Szymanski contributed equally to this study. The authors would like to thank Anna Last for her help and the Helen Bamber Foundation's staff and patients for their participation in this study.

\section{References}

1. American Psychiatric Association. Diagnostic and Statistical Manual of Mental Disorders DSM-III ( $3^{\text {rd }}$ ed.). Washington DC; 1980.

2. Herman J. Complex PTSD: A syndrome in survivors of prolonged and repeated trauma. J Trauma Stress. 1992; 5(3): 377-391.

3. Ford J, Kidd P. Early childhood trauma and disorders of extreme stress as predictors of treatment outcome with chronic posttraumatic stress disorder. J Trauma Stress. 1998; 11(4): 743-776.

4. Zucker M, Spinazzola J, Blaustein M, van der Kolk B. Dissociative symptomatology in posttraumatic stress disorder and disorders of extreme stress. J Trauma Dissociation. 2006; 7(1): 19-31.

5. Dorrepaal E, Thomaes K, Draijer P. Stabilisation therapy as an answer to complex post-traumatic stress disorder; diagnosis, treatment and research in women abused in childhood with a complex post-traumatic stress disorder. Tijdschr Psychiatry. 2006; 48(3): 217-222.

6. Ford J, Hawke J, Alessi S, Ledgerwood D, Petry N. Psychological trauma and PTSD symptoms as predictors of substance dependence treatment outcomes. Behav Res Ther. 2007; 45(10): 2417-2431

7. American Psychiatric Association. Diagnostic and Statistical Manual of Mental Disorders DSM-VI (4 ${ }^{\text {th }}$ ed.). Arlington, VA; 2000.

8. American Psychiatric Association. Diagnostic and Statistical Manual of Mental Disorders DSM-V ( $5^{\text {th }} \mathrm{ed}$.). Washington DC; 2013.

9. Cloitre M, Garvert D, Brewin C, Bryant R, Maercker A. Evidence for proposed ICD-11 PTSD and complex PTSD: A latent profile analysis. Eur J Psychotraumatol. 2013; 4. doi: 10.3402/ejpt.v4i0.20706

10. Pelcovitz D, van der Kolk B, Roth S, Mandel F, Kaplan S, Resick P. Development of a criteria set and a structured interview for disorders of extreme stress (SIDES). J Trauma Stress. 1997; 10(1): 3-17.

11. Zlotnick C, Pearlstein T. Validation of the structured interview of disorders of extreme stress. Compr Psychiatry. 1997; 38(4): 243-247.

12. De Jong J, Komproe I, Spinazzola J, van der Kolk B, van Ommeren M. DESNOS in three post-conflict settings: Assessing cross-cultural construct equivalence. J Trauma Stress. 2005; 18: 13-21.

13. Morina N, Ford J. Complex sequelae of psychological trauma among Kosovar civilian war victims. Int J Psychiatry Med. 2008; 54(5); 425-436. 
14. Weine S, Becker D, Vojvoda D, Hodzic E, Sawyer M, Hyman L, et al. Individual change after genocide in Bosnian survivors of ethnic cleansing: Assessing personality dysfunction. J Trauma Stress. 1998; 11(1): 147-153.

15. Teodorescu D, Heir T, Hauff E, Wentzel-Larsen T, Lien L. Mental health problems and post-migration stress among multi-traumatized refugees attending outpatient clinics upon resettlement to Norway. Scand J Psychol. 2012; 53(4): 316-322.

16. Oram S, Stockl H, Busza J, Howard L, Zimmerman C. Prevalence and risk of violence and the physical, mental and sexual health problems associated with human trafficking: Systematic review. PLoS Medicine. 2012; 9(5): e1001224.

17. Golding J. Intimate partner violence as a risk factor for mental disorders: a meta-analysis. J Fam Violence. 1999; 14(2): 99-132.

18. Steel Z, Chey T, Silove D, Marnane C, Bryant R, van Ommerren R. Association of torture and other potentially traumatic events with mental health outcomes among populations exposed to mass conflict and displacement: A systematic review and meta-analysis. JAMA. 2009; 302(5): 537-549.

19. Teegen F, Vogt S. Survivors of torture: a study of complex posttraumatic stress disorders. Verhaltenstherapie \& Verhaltensmedizin. 2002; 23(1): 91-106.

20. Teegen F, Schriefer J. Complex posttraumatic stress disorders: an investigation of the diagnostic construct in a sample of abused women. Z Klinische Psychol Psychiat Psychotherap. 2002; 50(2): 219-233.

21. United Nations Educational, Scientific and Cultural Organization (UNESCO). Social and Human Sciences: Asylum seeker. Available at: www.unesco.org/shs/migration/glossary [Accessed January 2014].

22. United Nations. Convention against torture and other cruel, inhuman or degrading treatment or punishment. No. 93
(A/RES/39/46); 1984. Available at: http://www.un.org/documents/ga/res/39/a39r046.htm [Accessed April 2013].

23. United Nations. UN convention against transnational organised crime and the protocols thereto, Protocol to prevent, suppress and punish trafficking in persons, especially women and children. No. 105 (A/RES/55/25); 2000. Available at: http://www.unodc.org/documents/treaties/UNTOC/Publications/TOC\%20Convention/TOCebook-e.pdf [Accessed April 2013].

24. The Home Office. Definition of domestic violence and abuse: guide for local areas; 2013. [pdf]. Available at: https://www.gov.uk/government/uploads/system/uploads/attachment_data/file/142701/guide-on-definition-of-dv.pdf [Accessed April 2013].

25. Dorahy M, Corry M, Shannon M, Macsherry A, Hamilton G, McRobert G, et al. Complex PTSD, interpersonal trauma and relational consequences: Findings from a treatment-receiving Northern Irish sample. J Affect Disord. 2009; 112(1): 71-80.

26. Ford J. Disorders of extreme stress following warzone military trauma: Associated features of posttraumatic stress disorder or comorbid but distinct syndromes? J Consult Clin Psychol. 1999; 67(1): 3-12.

27. Cloitre M, Courtois C, Charuvastra A, Carapezza R, Stolbach B, Green B. Treatment of complex PTSD: Results of the ISTSS expert clinician survey on best practices. J Trauma Stress. 2011; 24(6): 615-627.

Corresponding author:

Madeleine Kissane

20 Far Handstones

Bristol

BS30 8AU

E-mail:mjk905@bham.ac.uk. 